\title{
Sequencing and validation of housekeeping genes for quantitative real-time PCR during the gonadotrophic cycle of Diploptera punctata
}

\author{
Elisabeth Marchal, Ekaterina F Hult, Juan Huang and Stephen S Tobe*
}

\begin{abstract}
Background: Quantitative RT-PCR (q-RT-PCR) is a powerful tool that allows for the large scale analysis of small changes in gene expression. Accurate and reliable results depend on the use of stable reference genes for normalization. However, the expression of some widely used housekeeping genes can vary under different experimental setups. To our knowledge, no validation studies have been reported for reference genes in cockroaches. The aim of the current study is the identification and validation of a set of eight housekeeping genes during the first gonadotrophic cycle of the cockroach, Diploptera punctata. This study made use of two different algorithms (geNorm and Normfinder) to evaluate the stability of gene expression.

Results: Candidate housekeeping genes were sequenced: $\beta$-actin (Actin), elongation factor 1 alpha (EF1a), glyceraldehyde-3-phosphate dehydrogenase (GAPDH), armadillo (Arm), ribosomal protein L32 (RpL32), succinate dehydrogenase (SDHa), annexin IX (AnnIX) and a-tubulin (Tub). The expression of these eight genes was analyzed in corpora allata (CA) and ovaries of adult female D. punctata. Both geNorm, as well as Normfinder characterized SDHa, EFla and Arm as being the most stably expressed in the corpora allata. In the ovary, the geNorm calculation showed Tub, EF1a and RpL32 to be most stable, whereas Normfinder identified Tub, EF1a and Arm as the best. In ovary, the least stable gene was Actin, challenging its usefulness in normalization. As a proof of principle, the expression of follicle cell protein $3 c$ and CYP15A1 was monitored during the first gonadotrophic cycle.

Conclusion: Arm and EFla form the most stably expressed combination of two reference genes out of the eight candidates that were tested in the corpora allata. Our results show that the combined use of Tub, EF1a and RpL32 ensures an accurate normalization of gene expression levels in ovary of D. punctata. Our study has indicated that neither Actin nor AnnIX should be used for normalization of transcript levels when studying the first gonadotrophic cycle in CA or ovary of D. punctata. The results stress the necessity for validation of reference genes in q-RT-PCR studies in cockroaches.
\end{abstract}

Keywords: q-RT-PCR, Reference genes, GeNorm, Normfinder, Normalization, Diploptera punctata

\section{Background}

Given its very high sensitivity, q-RT-PCR is currently the method of choice to measure mRNA transcription levels for individual genes. Results of high-throughput techniques such as microarrays are often confirmed using this robust technique. Moreover, this assay is widely used for medical diagnostics purposes and in identification of disease-specific biomarkers [1-3]. However, the

\footnotetext{
* Correspondence: stephen.tobe@utoronto.ca

Department of Cell and Systems Biology, University of Toronto, 25 Harbord Street, Toronto, Canada
}

quality of the results depends on the use of the appropriate controls. The calculation of relative transcript levels requires normalization that will compensate for small differences in initial sample quantity, sample preparation and efficiency of cDNA synthesis. However, the use of unpredictable normalization factors can pose difficulties in using q-RT-PCR to accurately describe relative mRNA levels. A common method to normalize mRNA levels of genes of interest is the use of endogenous control genes, termed 'housekeeping' genes or reference genes. Ideally, the mRNA levels of these genes should be stable in all cell types and tissues and should not be regulated by 
internal or external influences in the experimental setup. Since literature suggests that the expression of commonly used reference genes can change in different experimental conditions or tissues and no universally valid reference gene exists, the choice of reference genes cannot be made a priori [4-8]. For this reason, several algorithms were developed to identify the most stably expressed references genes in any given experimental setup $[4,6,9]$. Accordingly, many studies aimed at finding the most suitable reference genes in a diverse array of cells, tissues, experimental treatments and different species are now being reported.

Although there have been several validation studies for reference genes in different invertebrate species [10-16], many expression studies in insects, however, still use only one reference gene and most expression studies in cockroaches have routinely used $\beta$-actin. Although limited sequence information is available on the more basal insect order Dictyoptera, the cockroach Diploptera punctata has proven to be an ideal model organism in the study of juvenile hormone (JH). JHs represent a family of sesquiterpenoid hormones synthesized in the CA, a pair of small endocrine organs located in the insect's head. JHs play important and diverse roles during insect life; for example, they are involved in the control of development, growth, aging, metamorphosis and reproduction $[17,18]$. D. punctata is the only known truly viviparous cockroach. Because of this remarkable feature, the rate of $\mathrm{JH}$ production is tightly controlled during the animal's reproductive cycle. High rates of JH biosynthesis in their CA are coordinated with a very precise and predictable order of reproductive events, making this cockroach an ideal model for studying the regulation of $\mathrm{JH}$ production [19-21]. Therefore, D. punctata has also been used in several studies aimed at identifying novel Insect Growth Regulators (IGRs) that can interfere with $\mathrm{JH}$ production [22-25]. Understanding different patterns of gene expression is essential in identifying factors that are important for biosynthesis, degradation, regulation and function of this crucial insect hormone.

The objective of the current study was to evaluate the optimal reference genes for use in normalization of gene transcript levels in CA and ovaries during the gonadotrophic cycle of $D$. punctata. Eight candidate reference genes were sequenced from embryo or adult ovary of $D$. punctata. Their expression levels and stability were measured in two tissues undergoing important cross-talk during the gonadotrophic cycle: the ovary and the CA. Two different algorithms were used to calculate the most stable reference genes in our setup. As a proof of principle, the relative mRNA quantity of two target genes was studied. A gene involved in choriogenesis (follicle cell protein $3 c$ ) was studied in the ovary and expression of CYP15A1, a gene encoding a cytochrome
P450 enzyme directly involved in the $\mathrm{JH}$ biosynthetic pathway was determined in the CA $[26,27]$.

\section{Results}

Physiological measurements of the sample animals

Oocyte length was determined for each dissected female cockroach used in the q-RT-PCR assays (Figure 1). A clear rising trend in length can be observed as vitellogenin is taken into the developing oocytes, as was previously described [28]. The sample animals ovulated at the start of day 7. Rates of $\mathrm{JH}$ release throughout the gonadotrophic cycle steadily rise until four days post final molt, a sharp decline can be seen on day 5 (Figure 1). The activity of the CA is linked to the cycle of egg development, as was reported by Tobe and Stay [21]: Rates of $\mathrm{JH}$ release increase as oocytes grow during vitellogenesis. Before oviposition, $\mathrm{JH}$ release decreases and remains at a low level during gestation.

\section{Sequencing of the candidate reference genes and target gene follicle cell protein $3 c$ ( $f c p 3 c$ )}

Partial sequences for eight new candidate reference genes and the target gene $f c p 3 c$ were cloned in $D$. punctata. PCR amplicons ranging in size from 270 to 1319 bp were generated from D. punctata ovary or embryo cDNA templates (see Additional file 1). Upon blastx National Center for Biotechnology Information (NCBI) database searches, the orthologs showed substantial similarity to the corresponding previously described reference genes in other insect species. The nine obtained sequences (Actin, EF1a, GAPDH, Arm, RpL32, SDHa,

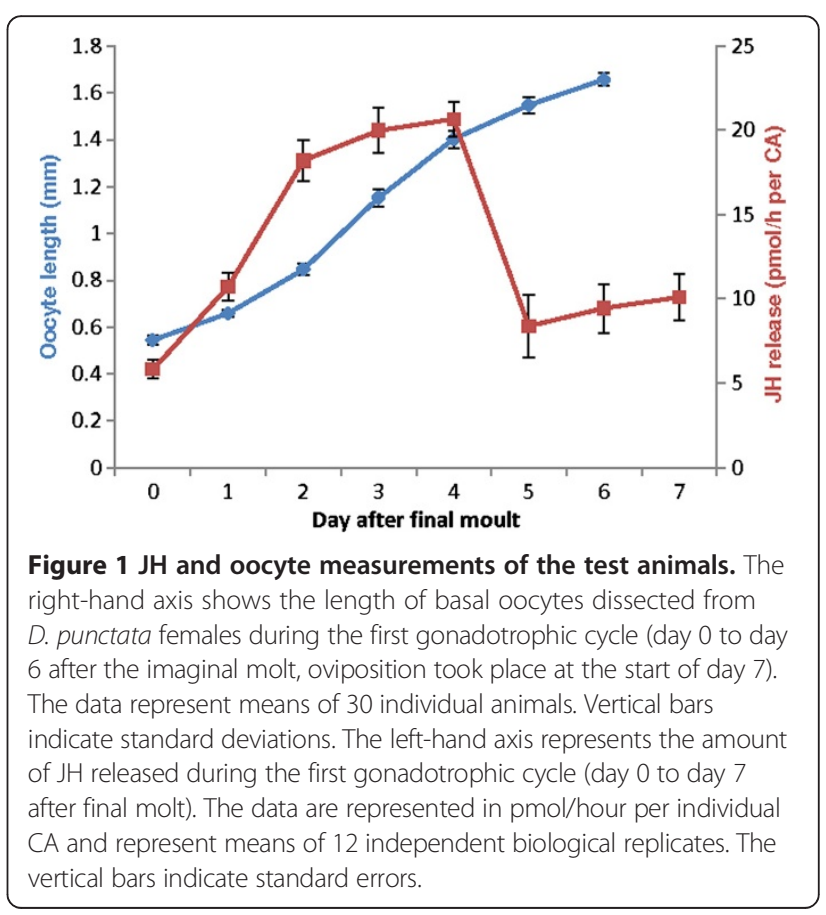


AnnIX, Tub and $f c p 3 c$ ) were uploaded on NCBI's GenBank and accession numbers were assigned (Table 1). The sequence of the target gene CYP15A1 was obtained from GenBank [GenBank: AY509244].

\section{Q-RT-PCR assays}

The initial screening of the eight potential reference genes showed that all of the genes were expressed in both CA and ovary of D. punctata. The primer efficiency (E) for each of the eight candidate genes was calculated using the slope acquired when measuring the fluorescence in 10-fold cDNA dilutions of a calibrator cDNA sample using the formula: $E=10^{1 / \text { slope }}-1$. Only primers that fell in the range $90-100 \%$ efficiency and showed $\mathrm{r}^{2}>0.95$ were considered for further analysis. The calculated efficiencies ranged from $90.8 \%$ (for $A n n I X$ ) to $100 \%$ (for GAPDH), the regression coefficients $\left(\mathrm{R}^{2}\right)$ varied from 0.975 (SDHa) to 0.995 (RpL32) (Table 2). No amplification of the fluorescent signal was detected in the negative control samples (-RT), proving that the RNA extraction methods and the DNase treatment procedures effectively eliminated genomic DNA from the RNA samples. Single amplicons were detected on $2 \%$ agarose gels of selected samples for each primer pair after the q-RTPCR protocol was run. These amplicons were cut out, gel-extracted, subcloned and sequenced, thereby confirming target specificity.

\section{Expression stability of the selected reference genes}

Variation of the Ct values among the 24 samples for the eight candidate reference genes is shown in Figure 2. Raw $\mathrm{Ct}$ values are given in Additional file 2. In the CA, the $\mathrm{Ct}$ values for the selected reference genes ranged from 20.33 (EF1a) to 30.62 (Arm). In the ovary, the $\mathrm{Ct}$ values ranged from 18.65 (EF1a) to 28.23 (Arm). Transcripts for EF1a and Arm were shown to be the most and least abundant expressions respectively in both tissue types tested. The $\mathrm{Ct}$ values between $\mathrm{CA}$ and ovary can, however, not be compared since the amount of RNA used to transcribe to cDNA was not the same.

Two different algorithms, GeNorm and Normfinder, were used to identify the genes that were most stably expressed in ovary and CA during the differing physiological conditions of the first gonadotrophic cycle.

The geNorm algorithm assumes that the candidate genes are not co-regulated. For each reference gene tested, geNorm calculates the gene expression stability value $M$ as the average pairwise variation for that gene with all other reference genes. Genes characterised by a low pairwise variation $M$ will therefore have stable expression. The gene with the highest $M$ value will be eliminated and this process is repeated until the two most stable genes are identified. This last pair of genes is recommended as the optimal pair of reference genes. The designers of the geNorm software recommend the use of at least two reference genes to ensure accurate

Table 1 Name, symbol, function, primer sequences and accession number for the housekeeping genes and the target gene

\begin{tabular}{|c|c|c|c|c|}
\hline Name & Symbol & Function & Degenerate primer sequences & $\begin{array}{l}\text { Accession number } \\
\text { (GenBank) }\end{array}$ \\
\hline \multirow[t]{2}{*}{ Actin 5C } & \multirow[t]{2}{*}{ Actin } & \multirow[t]{2}{*}{ Cytoskeletal structural protein } & F 5'-CATCAGGGAGTCATGGTCGGCA-3' & \multirow[t]{2}{*}{ JQ086312 } \\
\hline & & & R 5'-GCATACAGGTCTTTACGGATGTCC-3' & \\
\hline \multirow[t]{2}{*}{ Elongation factor 1 alpha } & \multirow[t]{2}{*}{ EF1-a } & \multirow[t]{2}{*}{ Protein synthesis } & F 5'-TTCGAGAAGGAAGCCCAGGARATGG-3' & \multirow[t]{2}{*}{ JQ086311 } \\
\hline & & & R 5'-CACDGAYGGACCAATCAGCACAYCT-3' & \\
\hline \multirow{2}{*}{$\begin{array}{l}\text { Glyceraldehyde-3-phosphate } \\
\text { dehydrogenase }\end{array}$} & \multirow[t]{2}{*}{ GAPDH } & \multirow[t]{2}{*}{ Glycolysis } & F 5'-ATGTCDAAGATYGGWATCAACGG-3' & \multirow[t]{2}{*}{ KC149901 } \\
\hline & & & R 5'-TTAGTCYTTKGACTGCATG-3' & \\
\hline \multirow[t]{2}{*}{ Armadillo } & \multirow[t]{2}{*}{ Arm } & \multirow[t]{2}{*}{ Cell adhesion } & F 5'-ATGGARGARATHGTNGARGGAAC-3' & \multirow[t]{2}{*}{ KC149902 } \\
\hline & & & R 5'-TTGTARTCYTGNGGYTTRTCYTC-3' & \\
\hline \multirow[t]{2}{*}{ Ribosomal protein L32 } & \multirow[t]{2}{*}{ RpL32 } & \multirow[t]{2}{*}{ Ribosomal structural constituent } & F 5'-AARCCNAARGGNATYGACAAYAG-3' & \multirow[t]{2}{*}{ KC149903 } \\
\hline & & & R 5'-CRCARTAYTTSCKRTTMTGCATCAT-3' & \\
\hline \multirow[t]{2}{*}{ Succinate dehydrogenase } & \multirow[t]{2}{*}{$\mathrm{SDHa}$} & \multirow[t]{2}{*}{ Energy metabolism } & F 5'-TGGCAGTGGCAYATGTAYGAY-3' & \multirow[t]{2}{*}{ KC149904 } \\
\hline & & & R 5'-GTYTGCATNGTYTTYTGCAT-3' & \\
\hline \multirow[t]{2}{*}{ Annexin IX } & \multirow[t]{2}{*}{ AnnIX } & \multirow[t]{2}{*}{ Cell differentiation, membrane fusion } & F 5'-AARTGYACYCCHACRGTRTAYCC-3' & \multirow[t]{2}{*}{ KC149905 } \\
\hline & & & R 5'-TTRATRTCMSCYARRTCNATYTC-3' & \\
\hline \multirow[t]{2}{*}{ a-tubulin } & \multirow[t]{2}{*}{ Tub } & \multirow[t]{2}{*}{ Cytoskeletal structural protein } & F 5'-ATGCGTGARTGTATHTCRRTBCA-3' & \multirow[t]{2}{*}{ KC149906 } \\
\hline & & & R 5'-GARTCCATNCCNACYTCYTCRTA-3' & \\
\hline \multirow[t]{2}{*}{ Follicle cell protein $3 c$} & \multirow[t]{2}{*}{ Fcp $3 c$} & \multirow[t]{2}{*}{ Vitellogenesis } & F 5'-TGYRYHTGTGGARTGTTYTTRA-3' & \multirow[t]{2}{*}{ KC149907 } \\
\hline & & & R 5'-TCYTTRCARCARTAYTCYCKWCC-3' & \\
\hline
\end{tabular}


Table 2 q-RT-PCR primer sequences, amplicon size, reaction efficiencies and correlation coefficients in q-RT-PCR assay for the selected references genes and the target genes follicle cell protein 3c and CYP15A1

\begin{tabular}{|c|c|c|c|c|c|}
\hline q-RT-PCR primers & Forward & Reverse & Amplicon size (bp) & Efficiency (\%) & $\mathrm{R}^{2}$ \\
\hline Actin & 5'-TCGCACACAGTACCAATCTATGAA-3' & 5'-CAAGTCACGACCAGCCAGATC-3' & 78 & 99.3 & 0.980 \\
\hline EF1-a & 5'-TCGTCTTCCTCTGCAGGATGTCT-3' & 5'-GGGTGCAAATGTCACAACCATACC-3' & 109 & 99.2 & 0.994 \\
\hline GAPDH & 5'-TCCGTGTGCCTGTTCCTAATG-3' & 5'-GCTGCCTTGCCAAGTCTGA-3' & 61 & 100 & 0.988 \\
\hline Arm & 5'-GCTACTGCACCACTCACAGAATTATT-3' & 5'-CTGCAGCATACGTTGCAACA-3' & 64 & 94.5 & 0.980 \\
\hline RpL32 & 5'-GCGCTTCAAGGGCCAGTAC-3' & 5'-TGCTTGGTTITCTTATTGCTACCA-3' & 63 & 97.4 & 0.995 \\
\hline $\mathrm{SDHa}$ & 5'-GCTCTTCTGTGCATGGTGCTAA-3' & 5'-GCACGTCCGAACACAACAAG-3' & 70 & 94.6 & 0.975 \\
\hline AnnIX & 5'-CAGAGGTTGGAGATTGCTGA-3' & 5'-TGCATCTTCAAATGCTCCTC-3' & 96 & 90.8 & 0.989 \\
\hline Tub & 5'-AAATTACCAACGCTTGCTTTGAA-3' & 5'-TGGCGAGGATCGCATTTT-3' & 58 & 95.1 & 0.993 \\
\hline Fcp 3c & 5'-TCTACCTTGCAACGCTITTG-3' & 5'-TCCCTGTCTATTGAGCCACA-3' & 111 & 92.9 & 0.975 \\
\hline CYP15A1 & 5'-GTTGGGATCTCGGAGCATGG -3' & 5'-CGAACACGTCATGCATCGGT -3' & 116 & 100 & 0.992 \\
\hline
\end{tabular}

normalization. Figures $3 \mathrm{~A}$ and $4 \mathrm{~A}$ show the average expression stability measures (AESM) of the set of reference genes tested in the CA and ovary respectively.

In the $\mathrm{CA}$, geNorm ranked the suite of candidate reference genes: Arm, SDHa > EF1a > Actin > RpL32>

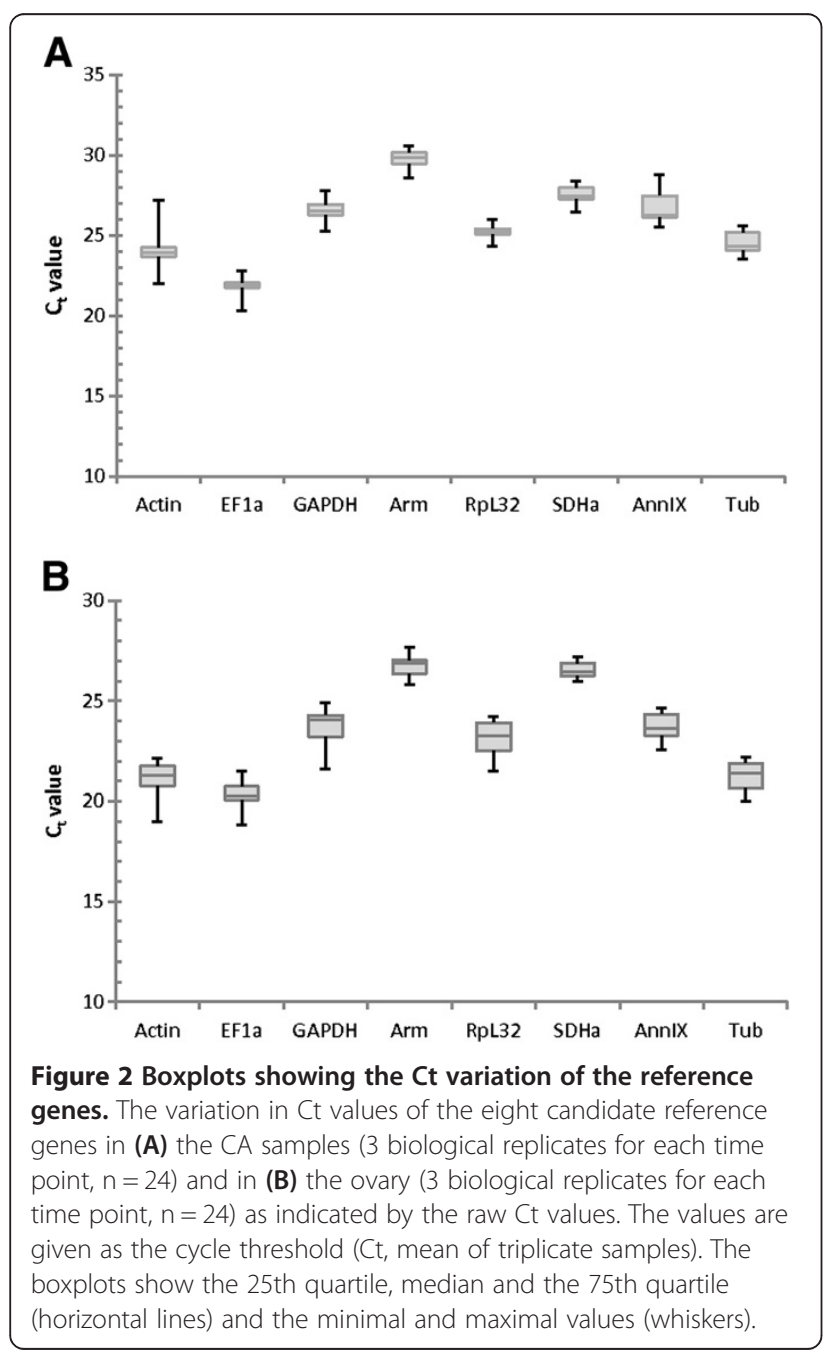

GAPDH > Tub > AnnIX. Arm and SDHa were found to be the most stable genes with an average expression stability $M$ of 0.364 . The gene with the least stable expression was $A n n I X$ with an M-value of 0.695 . In the ovary, use of the geNorm software provided the following ranking: RpL32, Tub > EF1a > GAPDH > SDHa > Arm > AnnIX > Actin. RpL32 and Tub were found to be the best genes to ensure accurate normalization with an $M$ value of 0.481 , and least stable was Actin $(\mathrm{M}=0.883)$.

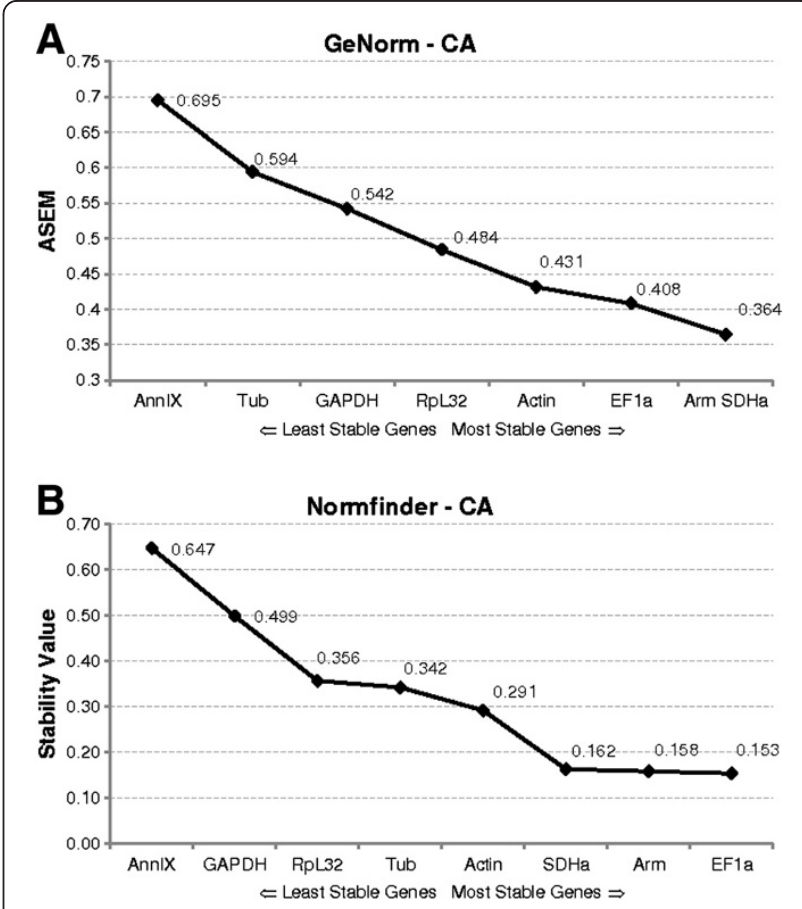

Figure 3 Stability values in the CA as generated by the two algorithms, A) geNorm and B) Normfinder. (A) The average expression stability values (AESM) from least stable (left) to most stable (right). Threshold for an unstable gene is $M \geq 1.5$. (B) The expression stability values from the candidate reference genes calculated by the Normfinder software. 


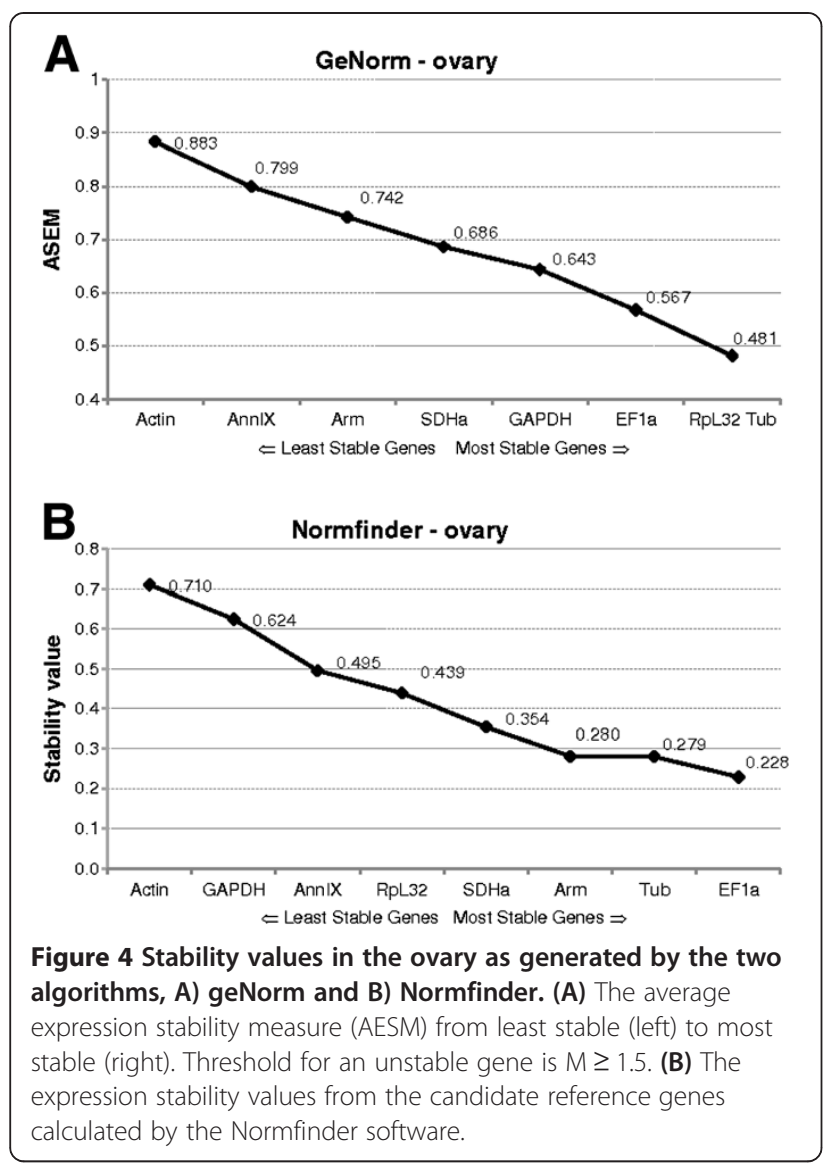

All genes were found to be sufficiently stable for use in normalization. GeNorm sets a threshold for an unstable gene as an AESM of 1.5, well above our maximal observed value of 0.695 and 0.883 in CA and ovary respectively.

In addition, geNorm can also determine the optimal number of genes required for accurate normalization. Upon inclusion of a less stable reference gene, geNorm calculates the pairwise variation (V) using sequential normalization factors (NFn and NFn +1 ). The algorithm can thus determine if addition of the extra reference gene will add to the stability of the normalization factor. A cut-off value of $\mathrm{V}=0.15$ is recommended in deciding the addition of the next reference gene. In the CA, the lowest $\mathrm{V}$-value was calculated following inclusion of the 7th most stable gene, this means that addition of the least stable gene $A n n I X$ would negatively impact the normalization process. This is similar in the ovary, in which inclusion of Actin would result in a poorer normalization. Our results indicate that in CA, only two reference genes are necessary for accurate normalization since the V2/3-value was found to be below the cut-off of 0.15 (Figure 5A). In the ovary however, addition of the third most stable gene (EF1a) is needed, but adding a fourth is not imperative (Figure $5 \mathrm{~B}$ ).
The Normfinder analysis is based on an ANOVA (analysis of variance) model. This algorithm determines the genes with the least variation in expression over the whole sample set and can, if applicable, consider systematic differences between sample subgroups. During the gonadotrophic cycle of $D$. punctata, Normfinder ranked the eight reference genes in the CA as follows: EF1a > Arm $>$ SDHa $>$ Actin $>$ Tub $>$ RpL32 $>$ GAPDH $>$ AnnIX (Figure $3 \mathrm{~B}$ ), with EF1a being the most stable with a stability value of 0.153 and $A n n I X$ being the least stable with a stability value of 0.647 . Calculation of stability values in the ovary resulted in: EF1a $>$ Tub $>A r m>$ SDHa $>$ RpL32 $>$ AnnIX $>$ GAPDH $>$ Actin, with stability values for the best and the worst reference genes as 0.228 and 0.710 for EF1a and Actin respectively (Figure 4B).

\section{Gene expression of target genes}

The selected set of reliable reference genes was used to analyze the relative expression of two target genes, follicle cell protein $3 c$ and CYP15A1 in the ovary and CA, respectively, during the first gonadotrophic cycle of $D$. punctata. As a proof of principle, the expression of both genes was measured using the recommended set of reference genes, as well as the gene that was determined to be the worst for normalization. The relative expression profile of follicle cell protein $3 \mathrm{c}$ is shown in Figure 6A.

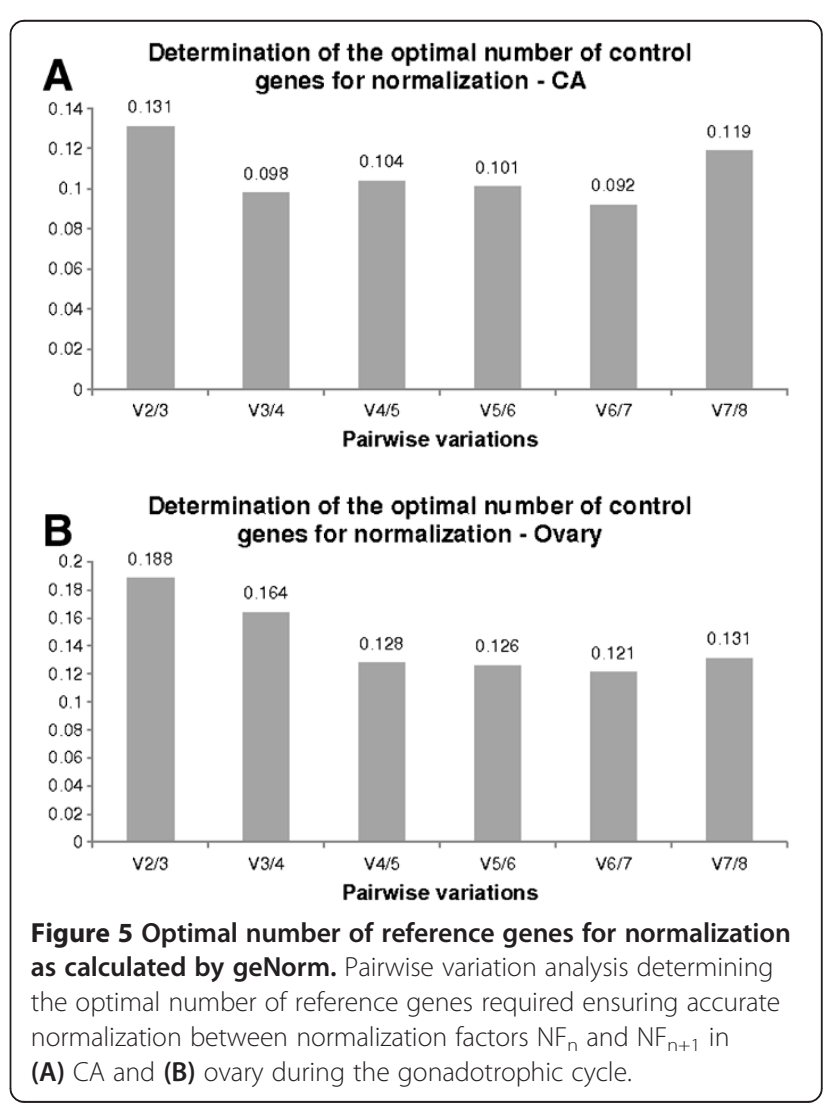


The results obtained by using Tub, EF1a and RpL32 as reference genes and their in-run PCR efficiency estimates show a high expression of $f c p 3 c$ on days 5 and 6 . However when the worst housekeeping gene, Actin was used to normalize, the relative expression on day 6 was found to be lower than when normalizing with the recommended set of reference genes.

The relative mRNA quantity of CYP15A1 normalized to the recommended set of housekeeping genes (EF1a and Arm) and to only $A n n I X$ is shown in Figure 6B. When performing normalization with EF1a and Arm the expression of CYP15A1 correlates with $\mathrm{JH}$ biosynthesis. However, when only normalized to AnnIX, CYP15A1

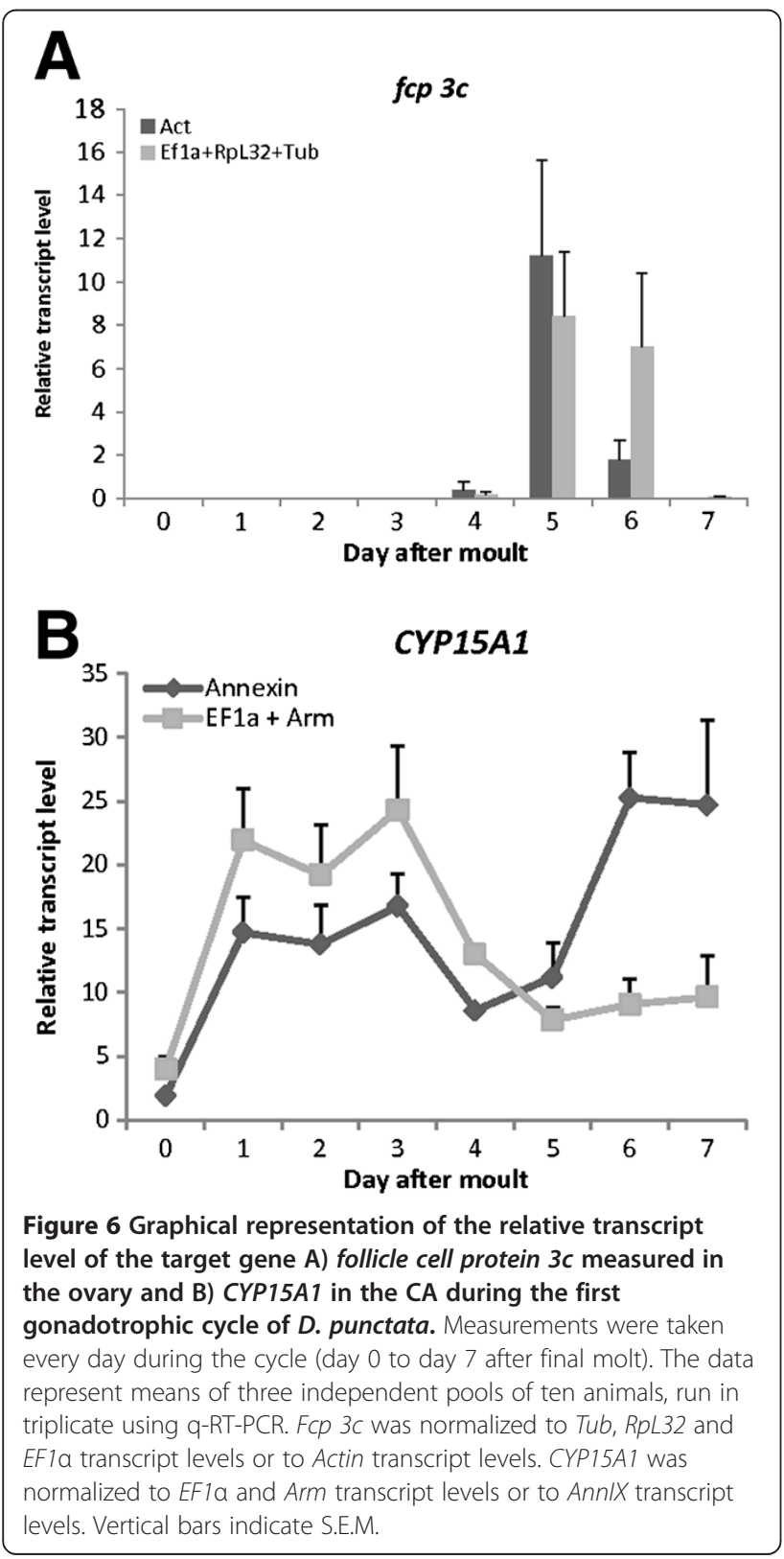

expression increases at the end of the gonadotrophic cycle when $\mathrm{JH}$ biosynthesis is low (Figure 1).

\section{Discussion}

The sensitivity and range of q-RT-PCR has ensured that this technique is the most important in relative quantification of mRNA levels. However, the accuracy of q-RTPCR studies using an internal control for normalization, is dependent on the reference genes used. The expression stability of these genes may be influenced by differences in the studied tissues, experimental treatments or physiological state. Therefore, the use of such genes without previous and proper validation for the experimental setup, can lead to the calculation of inaccurate expression levels of target genes and consequently to incorrect data interpretation [6]. To avoid bias from normalization, the use of multiple stably expressed references genes has become the gold standard in q-RT-PCR studies [29]. To our knowledge, a validation study of housekeeping genes for the relative quantification of mRNA has not been performed before in cockroaches. Unfortunately, to date, very limited sequence information is available for the Pacific beetle cockroach, $D$. punctata. Nevertheless, this animal is an appropriate model for endocrine studies of the reproductive cycle in primitive insects. This is especially true in studying the production and regulation of $\mathrm{JH}$. To gain more insight into these regulatory processes up- and downstream of $\mathrm{JH}$, q-RT-PCR was established for use as a robust technique to determine relative expression levels of target genes involved in the regulation of reproduction in this viviparous cockroach.

Eight possible reference genes were selected based on their traditional use and stability described in reported validation studies in other insects [10,12,13,16,30,31]. Next to the eight genes described in this study, one other gene widely used as a reference in other organisms, ubiquitin, was investigated. However, for the partial sequence that was picked up, the multiple q-RT-PCR primer pairs tested, did not result in single-band amplicons. The eight genes that were further investigated showed a relatively stable expression profile, characterised by AESM values far below the 1.5 cut-off value. Two tissues, CA and ovary, important in studying reproductive physiology, were chosen in this study. The stability of the eight genes during female development was followed from day 0 to day 7 after the imaginal molt. Both geNorm and Normfinder algorithms identified Arm, SDHa and EFIa as the most stable reference genes in the CA. By far the least stable was shown to be $A n n I X$. In the ovary, geNorm identified RpL32, Tub and $E F 1 a$ as the most stable, whereas the Normfinder analysis showed Tub, EF1a and Arm to be the most stably expressed. The consensus is that Tub and EF1a can be 
used to normalize the expression of target genes in the ovary. However, since Figure $5 \mathrm{~B}$ indicates that a third gene is necessary to ensure accurate normalization, the geometric mean of Tub, EF1a and RpL32 was used to normalize the expression of the target gene follicle cell protein 3c (Figure 6A). Differences in the outcome of both algorithms have been observed before [13,16,32,33] and can be explained by their calculation methods. Whereas geNorm eliminates the least stable gene in a stepwise manner and recalculates the AESM scores at each step, Normfinder follows a model-based approach, taking into account all the reference genes at one time. Moreover, geNorm assumes that the expression ratios $\mathrm{V}$ of two ideal reference genes are identical in all conditions. The program is therefore highly sensitive to coregulation, selecting genes with high degrees of similarity in their expression profiles. This disadvantage of geNorm was avoided by choosing candidate reference genes involved in different processes in cell housekeeping (Table 1). Other useful software, Bestkeeper, can be used to validate reference genes [9]. However, because this algorithm is similar to geNorm, its use was not included in this study.

Figure 5 shows that a large drop is seen in the V-value upon inclusion of a third or fourth reference gene for normalization in the CA or ovary respectively. A large drop in $\mathrm{V}$-value indicates a more accurate normalization with addition of the next best reference gene. However, since the V2/3 and V3/4 values in CA and ovary, respectively, are below the cut-off of 0.15 , the practicality and cost of using more reference genes in the q-RT-PCR setup must be considered.

As a proof of principle, our validation results were tested by measuring the expression of two target genes in the ovary. Follicle cell protein $3 c$ was found to be selectively expressed in follicle cells during the period of vitelline membrane formation in Drosophila melanogaster [34]. A very elegant study in the German cockroach, Blattella germanica designed a suppression subtractive hybridization library of the ovary aimed at identifying genes specifically expressed after vitellogenesis [27]. In this library, an ortholog of follicle cell protein $3 C$ was found. Its expression pattern showed a role in chorion formation. CYP15A1 was first functionally characterized in D. punctata. It encodes a cytochrome P450 enzyme catalyzing the epoxidation of methyl farnesoate to $\mathrm{JH}$ [26]. The gonadotrophic cycle has been well described in D. punctata. Mating of adult females on day 0 stimulates enhanced $\mathrm{JH}$ biosynthesis [35]. During the subsequent gonadotrophic cycle, both $\mathrm{JH}$ production and oocyte length rapidly increase, then as vitellin accumulates in the oocytes, JH synthesis declines on day 5 . After vitellin content reaches a maximum, the chorion forms and ovulation occurs on day 7 . At this time, the rate of $\mathrm{JH}$ production falls (as seen in Figure 1) and remains low during the gestation period [19,21]. The structure-activity relationship of the CA during the first gonadotrophic cycle of $D$. punctata has been described in great detail. A clear correlation exists between volume of CA cells, the number of cells per CA and the fine structure of organelles on the one hand and the $\mathrm{JH}$ biosynthetic capacity on the other. This increase in JH biosynthetic activity is not caused by an increase in cell number, but by an increase in the biosynthetic capacity per cell [36-38]. The expression pattern of Diploptera follicle cell protein $3 c$ as shown in Figure $6 \mathrm{~A}$ is consistent with the involvement of this gene in chorion formation, as earlier described for Blattella and Drosophila. When only normalized to Actin, the expression of $f_{c p} 3 c$ on day 6 drops relative to values normalized with the recommended set of reference genes; even though, on this day, chorion formation is still in full progress. In the case of CYP15A1, the expression rises drastically towards the end of the gonadotrophic cycle when only normalized to $A n n I X$ (Figure 6B). However, when normalizing with the recommended set of genes, CYP15A1 expression correlates well with the $\mathrm{JH}$ biosynthetic activity in the CA, as previously reported [26].

\section{Conclusion}

This study provides the first validation of reference genes for q-RT-PCR studies in cockroaches. Eight possible reference genes with relatively stable expression have been identified. Follow-up studies investigating relative mRNA levels in differing experimental setups will therefore become more straightforward. These results clearly show that some conventionally used reference genes such as $\beta$-actin may not be the best choice for normalization of gene expression in cockroaches and that it is important to always confirm the stability of reference genes in the specific system and experimental setup of interest.

\section{Methods}

\section{Animals}

The D. punctata colony was maintained at $27^{\circ} \mathrm{C}$ in constant darkness and animals were fed lab chow and water at libitum. To obtain pools of synchronised animals, newly molted female adult cockroaches were picked from the colony, placed in separate containers and provided with water and lab chow for the next 7 days. Mated status was confirmed by the presence of a spermatophore.

\section{Sample collection}

D. punctata adult females were dissected in cockroach ringer solution $(150 \mathrm{mM} \mathrm{NaCl}, 12 \mathrm{mM} \mathrm{KCl}, 10 \mathrm{mM}$ $\mathrm{CaCl}_{2} .2 \mathrm{H} 2 \mathrm{O}, 3 \mathrm{mM} \mathrm{MgCl} 2.6 \mathrm{H} 2 \mathrm{O}, 10 \mathrm{mM}$ HEPES, $40 \mathrm{mM}$ Glucose, $\mathrm{pH}$ 7.2) using a dissecting microscope. 
For each dissected animal, oocyte lengths were measured. CA and ovary samples were taken from day 0 to 7 of adult female development. Attached fat body was removed from tissues in sterile saline. Ovary and CA samples were flash-frozen in liquid nitrogen to prevent RNA degradation and were stored at $-80^{\circ} \mathrm{C}$ until further processing. For each time point, three biologically independent pools of 10 animals each were collected.

\section{RNA extraction and cDNA synthesis}

Pooled ovary samples were homogenised with RNasefree pestles and total RNA was extracted using the RNeasy Lipid Tissue Kit (Qiagen) according to the manufacturer's instructions. An additional DNase treatment (RNase-free DNase set, Qiagen) was performed to eliminate potential genomic DNA contamination. Because of the small size of the CA, RNA from this tissue was extracted using the RNAqueous-Micro Kit (Ambion), followed by the recommended DNase step. Quality and concentration of the resulting RNA samples were measured using a Nanodrop spectrophotometer (Thermo Scientific). Only intact RNA was used in subsequent PCR reactions. An equal amount of RNA (500 ng for ovary, $200 \mathrm{ng}$ for CA) was transcribed in subsequent cDNA synthesis utilising Superscript III and random hexamers in a final volume of $20 \mu \mathrm{l}$ following the manufacturer's protocol (Invitrogen Life Technologies). All samples were reverse transcribed together in a single run. The resulting cDNA samples were diluted 10 -fold with PCR grade water. A calibrator sample was prepared by pooling $5 \mu \mathrm{l}$ of each cDNA sample. In the same run, negative control reactions were set up without reverse transcriptase enzyme to test for genomic DNA contamination.

\section{Radiochemical assay (RCA)}

Rates of JH release were measured using the in vitro radiochemical assay (RCA) originally described by Tobe \& Pratt [39] and Pratt \& Tobe [40]. Day 0 to day 7 female cockroaches were immobilized on ice and their oocytes measured. CA were dissected and transferred to TC199 medium in a sterile environment. A short-term in vitro assay of JH release in TC199 medium (GIBCO) [2\% Ficoll, $1.3 \mathrm{mM} \mathrm{CaCl} 2 \cdot 2 \mathrm{H}_{2} \mathrm{O}$ and $3 \mu \mathrm{Ci} / \mathrm{ml} \mathrm{l-}\left[\right.$ methyl $\left.-{ }^{14} \mathrm{C}\right]$ methionine $(55 \mathrm{mCi} / \mathrm{mmol}$; American Radiolabeled Chemicals, Inc.) followed by rapid partition was conducted on individual corpora allata according to Feyereisen and Tobe [41] and Tobe and Clarke [42]. JH release was measured from 12 individual CA isolated from 12 different animals $(n=12)$.

\section{Sequencing of candidate reference genes}

Since no genome or full transcriptome sequence data is currently available for $D$. punctata, a first set of degenerate primers was developed based on a multiple sequence alignment of known orthologous sequences from different insects. Such an alignment was made for EF1- $\alpha$, GAPDH, armadillo, SDH, annexin, tubulin, RpL32 and for the target follicle cell protein 3c. For ß-actin, a Blattella germanica sequence is known and was used to design specific primers. Partial sequences for these genes were obtained with the primers listed in Table 1. A temperature-gradient polymerase chain reaction (PCR) was run using Taq DNA polymerase (Sigma-Aldrich Co.) with either $D$. punctata day 6 ovary or day 4 embryo cDNA as a template. In this PCR, the following thermocycling profile was used: $3 \mathrm{~min}$ at $95^{\circ} \mathrm{C}$ followed by 30 cycles of $30 \mathrm{~s}$ at $94^{\circ} \mathrm{C}, 1 \mathrm{~min}$ at $55^{\circ} \mathrm{C}$ (with a $10^{\circ} \mathrm{C}$ gradient) and $1 \mathrm{~min}$ at $72^{\circ} \mathrm{C}$. The amplification products were analyzed after a horizontal agarose gel electrophoresis and visualized using UV. Bands of the expected size were cut out and further purified using the GenElute ${ }^{\mathrm{Tm}}$ Gel extraction Kit (Sigma-Aldrich Co.). The resulting DNA fragments were subcloned into a CloneJET ${ }^{\mathrm{Tm}}$ cloning vector using the CloneJET ${ }^{\mathrm{T}}$ PCR Cloning Kit (Fermentas) and sequenced.

\section{Quantitative real-time PCR (q-RT-PCR)}

q-RT-PCR primers were designed using Primer Express software (Applied Biosystems) (Table 2). Primer sets were validated by designing relative standard curves for gene transcripts with serial 10-fold dilutions of the calibrator's cDNA sample. Efficiency of q-RT-PCR and correlation coefficient $\left(R^{2}\right)$ were measured for each primer pair.

q-RT-PCR reactions were performed in triplicate on a CFX384 Touch $^{\mathrm{Tm}}$ Real-Time PCR Detection System (Bio$\mathrm{Rad})$ in a $10 \mu \mathrm{l}$ volume containing $5 \mu \mathrm{IQ} \mathrm{IQ}^{\mathrm{m}} \mathrm{SYBR}^{\odot}$ Green Supermix (Bio-Rad), $1 \mu \mathrm{l}$ forward and reverse primer $(5 \mu \mathrm{M}), 2 \mu \mathrm{l}$ of MQ-water and $1 \mu \mathrm{l}$ of cDNA. A two-step thermal cycling profile was used: $95^{\circ} \mathrm{C}$ for $3 \mathrm{~min}$, followed by 40 cycles of $95^{\circ} \mathrm{C}$ for $10 \mathrm{~s}$ and $59^{\circ} \mathrm{C}$ for $30 \mathrm{~s}$. Upon completion of every run, a dissociation protocol (melt curve analysis) was performed to check for primer dimers. Additionally, a few representative PCR products were run on a $1.2 \%$ agarose gel containing GelRed $^{\text {TM }}$ (Biotium). After electrophoresis only a single band could be seen which was further cloned and sequenced (CloneJET $^{\mathrm{TM}}$ PCR Cloning Kit, Fermentas) to confirm target specificity.

Three biologically independent pools (each containing CA/ovary from 10 different animals) taken at each time point measured, were used to obtain the described results.

\section{Gene stability analysis}

The quantitative expression measurements relative to the calibrator sample of all the candidate reference genes tested in either CA or ovary during the gonadotrophic cycle were analyzed using the available normalization programs 
geNorm [6] and Normfinder [4], available from the website of the authors: http://medgen.ugent.be/ jvdesomp/genorm/ and http://www.mdl.dk/publicationsnormfinder.htm, respectively. Relative mRNA levels of follicle cell protein $3 c$ and CYP15A1 were normalized to the geometric mean of the relative quantity values for the required amount of most stably expressed reference genes selected by geNorm and NormFinder or to the relative quantity of the worst reference gene and relative to the calibrator sample [6].

\section{Available supporting data}

The sequence information on the genes described in this paper is available in NCBI GenBank (http://www.ncbi. nlm.nih.gov/genbank/).

\section{Additional files}

Additional file 1: Partial sequences of the eight candidate reference genes cloned from $D$. punctata. Q-RT-PCR primers are indicated in italics and underlined.

Additional file 2: Raw data of the q-RT-PCR assays for CA and ovary.

\section{Competing interests}

The authors declare that they have no competing interests.

\section{Authors' contributions}

This study was conceived and coordinated by EM and SST. EM, EFH and JH designed the experimental protocol. JH, EM and EFH reared the cockroaches and performed the dissections. JH performed all RNA extractions and RCA. $\mathrm{JH}$ and EM prepared CDNA samples. EM and EFH selected the reference genes, cloned and sequenced PCR products for the eight candidate genes, designed and tested primers for q-RT-PCR, performed the q-RT-PCRs and carried out the analyses. EM wrote the manuscript with help from EFH, JH and SST; all authors read and approved the final manuscript.

\section{Acknowledgements}

This work was supported by a Natural Science and Engineering Research Council of Canada grant to SST. JH was supported by a China Scholarship Council doctoral award. The authors are very grateful to Dr. Jennifer Mitchell for use of the q-RT-PCR equipment.

Received: 17 December 2012 Accepted: 11 June 2013

Published: 19 June 2013

\section{References}

1. Bartels $\mathrm{CL}$, Tsongalis GJ: MicroRNAs: novel biomarkers for human cancer. Clin Chem 2009, 55:623-631.

2. Bustin SA, Mueller R: Real-time reverse transcription PCR (qRT-PCR) and its potential use in clinical diagnosis. Clin Sci (Lond) 2005, 109:365-379.

3. Lohmann S, Herold A, Bergauer T, Belousov A, Betzl G, Demario M, Dietrich M, Luistro L, Poignee-Heger M, Schostack K, et al: Gene expression analysis in biomarker research and early drug development using function tested reverse transcription quantitative real-time PCR assays. Methods 2012, 59:10-19.

4. Andersen $C L$, Jensen $J$, Orntoft TF: Normalization of real-time quantitative reverse transcription-PCR data: a model-based variance estimation approach to identify genes suited for normalization, applied to bladder and colon cancer data sets. Cancer Res 2004, 64:5245-5250.

5. Schmittgen TD, Zakrajsek BA: Effect of experimental treatment on housekeeping gene expression: validation by real-time, quantitative RT-PCR. J Biochem Biophys Methods 2000, 46:69-81.

6. Vandesompele J, De Preter K, Pattyn F, Poppe B, Van Roy N, De Paepe A Speleman F: Accurate normalization of real-time quantitative RT-PCR data by geometric averaging of multiple internal control genes. Genome Biol 2002, 3:0034.
7. Chechi K, Gelinas Y, Mathieu P, Deshaies Y, Richard D: Validation of reference genes for the relative quantification of gene expression in human epicardial adipose tissue. PLOS One 2012, 7:e32265.

8. Dheda K, Huggett JF, Bustin SA, Johnson MA, Rook G, Zumla A: Validation of housekeeping genes for normalizing RNA expression in real-time PCR. Biotechniques 2004, 37(116):112-114-118-119.

9. Pfaffl MW, Tichopad A, Prgomet C, Neuvians TP: Determination of stable housekeeping genes, differentially regulated target genes and sample integrity: BestKeeper-Excel-based tool using pair-wise correlations. Biotechnol Lett 2004, 26:509-515.

10. Chapuis MP, Tohidi-Esfahani D, Dodgson T, Blondin L, Ponton F, Cullen D, Simpson SJ, Sword GA: Assessment and validation of a suite of reverse transcription-quantitative PCR reference genes for analyses of densitydependent behavioural plasticity in the Australian plague locust. BMC Mol Biol 2011, 12:7.

11. Hornakova D, Matouskova P, Kindl J, Valterova I, Pichova I: Selection of reference genes for real-time polymerase chain reaction analysis in tissues from Bombus terrestris and Bombus lucorum of different ages. Anal Biochem 2010, 397:118-120.

12. Maroniche GA, Sagadin M, Mongelli VC, Truol GA, Del Vas M: Reference gene selection for gene expression studies using RT-qPCR in virus-infected planthoppers. Virol J 2011, 8:308.

13. Paim RM, Pereira MH, Di Ponzio R, Rodrigues JO, Guarneri AA, Gontijo NF, Araujo RN: Validation of reference genes for expression analysis in the salivary gland and the intestine of Rhodnius prolixus (Hemiptera, Reduviidae) under different experimental conditions by quantitative real-time PCR. BMC Res Notes 2012, 5:128.

14. Ponton F, Chapuis MP, Pernice M, Sword GA, Simpson SJ: Evaluation of potential reference genes for reverse transcription-qPCR studies of physiological responses in Drosophila melanogaster. I Insect Physiol 2011, 57:840-850

15. Spanier KI, Leese F, Mayer C, Colbourne JK, Gilbert D, Pfrender ME, Tollrian R: Predator-induced defences in Daphnia pulex: Selection and evaluation of internal reference genes for gene expression studies with real-time PCR. BMC Mol Biol 2010, 11:50.

16. Van Hiel MB, Van Wielendaele $P$, Temmerman $L$, Van Soest $S$, Vuerinckx $K$, Huybrechts R, Broeck JV, Simonet G: Identification and validation of housekeeping genes in brains of the desert locust Schistocerca gregaria under different developmental conditions. BMC Mol Biol 2009, 10:56.

17. Goodman WG, Granger NA: The juvenile hormones. In Comprehensive Molecular Insect Science. Edited by Gilbert LI, latrou K, Gill SS. Oxford: Elsevier; 2005:319-408.

18. Verma KK: Polyphenism in insects and the juvenile hormone. $Z$ Naturforsch $C$ 2007, 32:415-420.

19. Stay B, Tobe SS: Control of the corpora allata during a reproductive cycle in a viviparous cockroach. Am Zool 1981, 21:663-674.

20. Tobe SS, Pratt GE: Corpus allatum activity in vitro during ovarian maturation in the desert locust, Schistocerca gregaria. J Exp Biol 1975, 62:611-627

21. Tobe SS, Stay B: Corpus allatum activity in vitro during reproductive cycle of viviparous cockroach, Diploptera punctata (Eschscholtz). Gen Comp Endocr 1977, 31:138-147.

22. Kai ZP, Huang J, Tobe SS, Yang XL: A potential insect growth regulator: synthesis and bioactivity of an allatostatin mimic. Peptides 2009, 30:1249-1253.

23. Kai ZP, Huang J, Xie Y, Tobe SS, Ling Y, Zhang L, Zhao YC, Yang XL: Synthesis, biological activity, and hologram quantitative structure-activity relationships of novel allatostatin analogues. J Agric Food Chem 2010, 58:2652-2658.

24. Lenkic LE, Tiu SH, Tobe SS: Suppression of JH biosynthesis by JH analog treatment: mechanism of suppression and roles of allatostatins and nervous connections in the cockroach Diploptera punctata. J Insect Physiol 2009, 55:967-975.

25. Xie Y, Kai ZP, Tobe SS, Deng XL, Ling Y, Wu XQ, Huang J, Zhang L, Yang XL: Design, synthesis and biological activity of peptidomimetic analogs of insect allatostatins. Peptides 2011, 32:581-586

26. Helvig C, Koener JF, Unnithan GC, Feyereisen R: CYP15A1, the cytochrome P450 that catalyzes epoxidation of methyl farnesoate to juvenile hormone III in cockroach corpora allata. Proc Natl Acad Sci USA 2004, 101:4024-4029.

27. Irles $P$, Belles $X$, Piulachs MD: Identifying genes related to choriogenesis in insect panoistic ovaries by Suppression Subtractive Hybridization. BMC Genomics 2009, 10:206. 
28. Mundall EC, Tobe SS, Stay B: Vitellogenin fluctuations in hemolymph and fat body and dynamics of uptake into oocytes during the reproductive cycle of Diploptera punctata. J Insect Physiol 1981, 27:821-827.

29. Bustin SA, Benes V, Garson JA, Hellemans J, Huggett J, Kubista M, Mueller R, Nolan T, Pfaffl MW, Shipley GL, et al: The MIQE guidelines: minimum information for publication of quantitative real-time PCR experiments. Clin Chem 2009, 55:611-622.

30. Scharlaken B, De Graaf DC, Goossens K, Brunain M, Peelman LJ, Jacobs FJ: Reference gene selection for insect expression studies using quantitative real-time PCR: the head of the honeybee, Apis mellifera, after a bacterial challenge. J Insect Sci 2008, 8:33.

31. Shen GM, Jiang HB, Wang XN, Wang JJ: Evaluation of endogenous references for gene expression profiling in different tissues of the oriental fruit fly Bactrocera dorsalis (Diptera: Tephritidae). BMC Mol Biol 2010, 11:76.

32. Mehta R, Birerdinc A, Hossain N, Afendy A, Chandhoke V, Younossi Z, Baranova A: Validation of endogenous reference genes for qRT-PCR analysis of human visceral adipose samples. BMC Mol Biol 2010, 11:32.

33. Sorby LA, Andersen SN, Bukholm IRK, Jacobsen MB: Evaluation of suitable reference genes for normalization of real-time reverse transcription PCR analysis in colon cancer. J Exp Clin Canc Res 2010, 29:144.

34. Burke T, Waring GL, Popodi E, Minoo P: Characterization and sequence of follicle cell genes selectively expressed during vitelline membrane formation in Drosophila. Dev Biol 1987, 124:441-450.

35. Ruegg RP, Lococo DJ, Tobe SS: Control of corpus allatum activity in Diploptera punctata - Roles of the pars intercerebralis and pars lateralis. Experientia 1983, 39:1329-1334.

36. Johnson GD, Stay B, Chan KK: Structure-activity relationships in corpora allata of the cockroach Diploptera punctata: roles of mating and the ovary. Cell Tissue Res 1993, 274:279-293.

37. Johnson GD, Stay B, Rankin SM: Ultrastructure of corpora allata of known activity during the vitellogenic cycle in the cockroach Diploptera punctata. Cell Tissue Res 1985, 239:317-327.

38. Szibbo CM, Tobe SS: Cellular and volumetric changes in relation to the activity cycle in the corpora allata of Diploptera punctata. J Insect Physiol 1981, 27:655-665.

39. Tobe SS, Pratt GE: The influence of substrate concentrations on the rate of insect juvenile hormone biosynthesis by corpora allata of the desert locust in vitro. Biochem J 1974, 144:107-113.

40. Pratt GE, Tobe SS: Juvenile hormones radiobiosynthesised by corpora allata of adult female locusts in vitro. Life Sci 1974, 14:575-586.

41. Feyereisen R, Tobe SS: A rapid partition assay for routine analysis of juvenile hormone release by insect corpora allata. Anal Biochem 1981, 111:372-375.

42. Tobe SS, Clarke N: The effect of L-methionine concentration on juvenile hormone biosynthesis by corpora allata of the cockroach Diploptera punctata. Insect Biochem 1985, 15:175-179.

doi:10.1186/1756-0500-6-237

Cite this article as: Marchal et al: Sequencing and validation of housekeeping genes for quantitative real-time PCR during the gonadotrophic cycle of Diploptera punctata. BMC Research Notes 2013 6:237.

\section{Submit your next manuscript to BioMed Central and take full advantage of:}

- Convenient online submission

- Thorough peer review

- No space constraints or color figure charges

- Immediate publication on acceptance

- Inclusion in PubMed, CAS, Scopus and Google Scholar

- Research which is freely available for redistribution 